\title{
Forging Optimization and Microstructural Simulation of an Inconel 718 Alloy Used in Turbine Discs
}

\author{
Seyyed Hashem Mousavi Anijdan*, Mehrdad Aghaie-Khafri, Vahid Joshaghani \\ Faculty of Materials Science and Engineering, K. N. Toosi University of Technology, Tehran, Iran \\ Email: ${ }^{\star}$ hashemmousavi@gmail.com
}

How to cite this paper: Anijdan, S.H.M., Aghaie-Khafri, M. and Joshaghani, V. (2017) Forging Optimization and Microstructural Simulation of an Inconel 718 Alloy Used in Turbine Discs. Journal of Applied Mathematics and Physics, 5, 1658-1667.

https://doi.org/10.4236/jamp.2017.59138

Received: June 31, 2017

Accepted: September 12, 2017

Published: September 15, 2017

\begin{abstract}
Simulating microstructure evolution during forging of superalloys is of great interest for manufacturer of critical components, particularly in aerospace applications. In this research, a phenomenological approach using a mathematical model was employed into a commercial finite element code, i.e. Abaqus, to study recrystallization and grain growth of IN718 supperalloys during forging. Model validation was performed by compression testing. Results show that the measured recrystallized volume fraction and the grain size were in good agreement with the model predictions. Subsequently, the model was used to simulate the evolution of microstructure in a turbine disc. Finally, a technique based on Tagushi method was used to determine the influence of forging parameters such as forging temperature, ingot height to diameter ratio, and top die velocity on the resultant microstructure. Uniform and refined microstructure of final forging was considered into the objective function. Optimum as well as the poorest parameters combination was attained through $S / N$ analysis. As well the contribution of each parameter on microstructure development was determined through variance analysis.
\end{abstract}

\section{Keywords}

Forging, Turbine Disc, Inconel 718 Alloy. Tagushi, ANOVA Analysis, Microstructure

\section{Introduction}

A turbine extracts energy from a hot gas flow to drive the compressor and the accessory gearbox. As inlet gas temperature of the gas turbine engine increases, 
its efficiency gets better. Therefore, the parts used in the turbine require to be made from superalloys which can operate in high temperature and high pressure with superior efficiency.

The turbine disc, as the object of this study is the rotating part which supports the turbine blades. During operation, gas turbine discs operate under severe conditions, such as high stress combined with centrifugal force and thermal gradient. These severe working environments require a proper forging of the disc to be performed. Grain size control in the forging of the Inconel 718 superalloy is a very important issue because the grain size is closely related to the mechanical properties and the performance of the discs [1] [2]. Na et al. [3] studied the evolution of the microstructure in the process of two-step blade forging of 718 alloy using a 3D FE simulator that contained a microstructure module. Also, Medeiros et al. [4] characterized the hot deformation behavior of IN718 alloy and obtained a relationship between the microstructure evolution and the processing map using compression testing. Zhang et al. [5] developed microstructure evolution model and studied the effect of forging parameters on the microstructure based on the processing maps in disc forging of 718 alloy. As well, in terms of optimization efforts, He et al. [6] used Tagushi method to optimize the microstructure in cylinder upsetting. In the present study a microstructure evolution model was implemented into a commercial finite element, i.e. Abaqus. A robust technique based on Tagushi method was presented to determine the influence of forging parameters on the microstructure evolution and to obtain the optimum combination of forging parameters in turbine disc forging.

\section{Method}

The objective of this study was to investigate the influence of forging parameters on the microstructure uniformity and smallness in to improve mechanical properties of heavy forgings. To achieve these goals the following steps were taken into account. First, the microstructure objective function was defined and the forging parameters were defined. Then, an appropriate orthogonal array was constructed. After the above steps, proper constitutive equations and microstructural models were implemented into Abaqus simulation software and finite element simulations were performed based on the arrangement of orthogonal array. Additionally, the results of the simulations were transferred into the Tagushi signal-to-noise $(\mathrm{S} / \mathrm{N})$ ratio. By doing this an optimum and poorest combinations of forging parameters were obtained. Finally, variance analysis (ANOVA) was performed to determine the significance of each parameter under investigation.

\section{Constitutive Equation}

To add the influence of strain rate and temperature on the flow stress, Johsnon-Cook plasticity model was used in the simulations. The Johsnon-Cook plasticity model is follows: 


$$
\sigma=\left[A+B\left(\bar{\varepsilon}^{p l}\right)^{n}\right]\left[1+C \ln \left(\frac{\dot{\bar{\varepsilon}}^{p l}}{\dot{\varepsilon}_{0}}\right)\right]\left(1-\hat{\theta}^{m}\right)
$$

where $\sigma$ is the yield stress, $\bar{\varepsilon}^{p l}$ is the equivalent plastic strain, $\dot{\bar{\varepsilon}}^{p l}$ is the equivalent plastic strain rate, $A, B, C, n, m, \dot{\varepsilon}_{0}$ are the material parameters measured at or below the transition temperature, and $\hat{\theta}$ is nondimensional temperature defined as:

$$
\hat{\theta}=\left\{\begin{array}{lc}
0 & \text { for } \theta<\theta_{\text {transition }} \\
\left(\theta-\theta_{\text {transition }}\right) /\left(\theta_{\text {melt }}-\theta_{\text {transition }}\right) & \text { for } \theta_{\text {transition }} \leq \theta \leq \theta_{\text {melt }} \\
1 & \text { for } \theta>\theta_{\text {melt }}
\end{array}\right.
$$

where $\theta$ is the current temperature, $\theta_{\text {transition }}$ is the transition temperature defined as the one at or below which there is no temperature dependence on the expression of the yield stress. $\theta_{\text {transition }}$ was considered equal to room temperature. The material parameters of the Johsnon-Cook plasticity model for Inconel 718 alloy are listed in Table 1 .

\section{Microstructural Model}

From the true stress vs. true strain curves, obtained under various strain rates and temperatures, one can deduce the variation of hardening rate with strain. Also, the critical strain $\left(\varepsilon_{c}\right)$ for the onset of dynamic recrystallization can be obtained from the inflection point in the curves. The detailed approach is explained elsewhere [7]. The critical strain was about 0.8 times the peak strain, which corresponds to the peak stress in the plot of the true strain vs. true strain. The critical strain is expressed as a function of initial grain size $\left(d_{0}\right)$ and Zener-Holloman parameter $(Z)$ in Table 2 . Generally, dynamic recrystallization

Table 1. Johsnon-Cook plasticity model parameters of Inconel 718.

\begin{tabular}{ccccccc}
\hline variable & $\dot{\varepsilon}_{0}$ & $A$ & $B$ & $C$ & $n$ & $m$ \\
\hline unit & $1 / \mathrm{s}$ & Mpa & Mpa & & & \\
value & 0.001 & 450 & 1700 & 0.017 & 0.65 & 1.3 \\
\hline
\end{tabular}

Table 2. Mathematical models for the microstructure evolution during forging of Inconel

\begin{tabular}{|c|c|c|}
\hline \multicolumn{3}{|c|}{ Critical strain } \\
\hline$\varepsilon_{c}=8.87 \times 10^{-4} d_{0}^{0.2} Z^{0.099}$ & when & $\dot{\varepsilon} \geq 0.01 \mathrm{~s}^{-1}$ \\
\hline$\varepsilon_{c}=9.57 \times 10^{-6} d_{0}^{0.196} Z^{0.167}$ & when & $\dot{\varepsilon}<0.01 \mathrm{~s}^{-1}$ \\
\hline \multicolumn{3}{|c|}{ Dynamic recrystallization } \\
\hline \multicolumn{3}{|c|}{$X_{d y n}=1-\exp \left(-\ln 2\left(\frac{\varepsilon}{\varepsilon_{0.5}}\right)^{1.68}\right.$ when $T \leq 1038^{\circ} C, \varepsilon_{0.5}=0.037 d_{0}^{0.2} Z^{0.058}$} \\
\hline \multicolumn{3}{|c|}{$X_{d y n}=1-\exp \left(-\ln 2\left(\frac{\varepsilon}{\varepsilon_{0.5}}\right)^{1.90}\right.$ when $T>1038^{\circ} C, \varepsilon_{0.5}=0.029 d_{0}^{0.2} Z^{0.058}$} \\
\hline \multicolumn{3}{|c|}{$d_{d y n}=1301 \times Z^{-0.124}$} \\
\hline \multicolumn{3}{|c|}{ Grain growth } \\
\hline \multicolumn{3}{|c|}{$d^{3}-d_{0}^{3}=9.8 \times 10^{19} t \exp (-43700 / R T)$} \\
\hline
\end{tabular}
718 alloy. 
occurs near grain boundaries forming a necklace microstructure. This is shown in Figure 1. The variation of the volume fraction of dynamically recrystallized grains $\left(X_{d y n}\right)$ versus strain was fitted to an Avrami-type equation. Dynamically recrystallized grain size $\left(d_{d y n}\right)$ was then expressed as a function of Zener-Holloman parameter as suggested by Shen et al. [8].

Dynamic recrystallization results show different behavior below and above $1038^{\circ} \mathrm{C}$ which is the dissolution temperature of $\delta$ phase. This phase acts as an obstacle against boundary movement.

\section{Verification of Microstructure Model}

To verify the above theoretical microstructure models, the simulation results using FEM, combined with microstructure models were compared with the experimental results in the literature [3]. H. Zhang et al. [3] conducted a non-isothermal upsetting experiment on a cylindrical specimen of 718 alloy with a diameter of 8 $\mathrm{mm}$ and a height of $12 \mathrm{~mm}$. 50 percent reduction in height was applied. The deformation temperature of the workpiece was $1000^{\circ} \mathrm{C}$. The die temperature was $300^{\circ} \mathrm{C}$ and the initial grain size was $32 \mu \mathrm{m}$. The grain size simulation results (Figure 2) were in good agreement with the measurements of the grain size in different zones of workpiece (Figure 3).
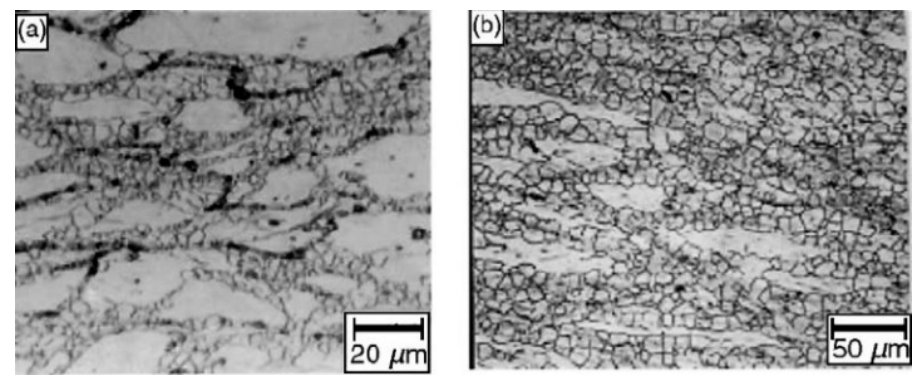

Figure 1. Dynamic recrystallization occurring near given boundary after compression tests at: (a) $954^{\circ} \mathrm{C}, 5 \mathrm{~s}^{-1}$ (b) $1066^{\circ} \mathrm{C}, 5 \mathrm{~s}^{-1}[1]$.

Grain size $(\mu \mathrm{m})$

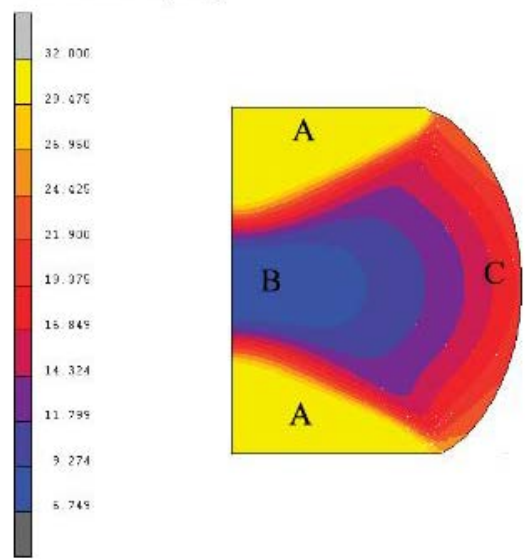

Figure 2. Grain size simulation result of superalloy 718 alloy during non-isothermal forging [5]. 
To validate the microstructure models, upsetting of 718 alloy specimen was simulated with Abaqus using the same conditions as mentioned above. Figure 4 shows the result of the grain size simulations which is in good agreement with the results of $\mathrm{H}$. Zhang et al. [5].

In both Figure 2 and Figure 4 three deformation zones can be identified. Dead zone A, easy deformation zone B and free deformation zone C. During deformation, because of the effect of heat exchange and the friction with the die, the top and the bottom of the workpiece are the dead zones. For the material located in these zones, dynamic recrystallization hardly takes place, as shown in Figure 3(a). As well, as dynamic recrystallization completes, a uniform and fine microstructure is obtained in the easy deformation zone B (Figure $3(b)$ ). In the

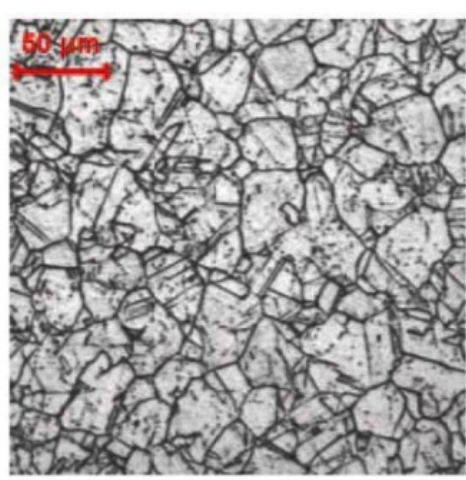

(a)

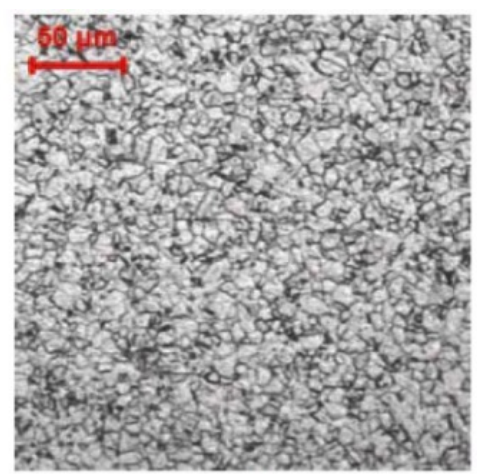

(b)

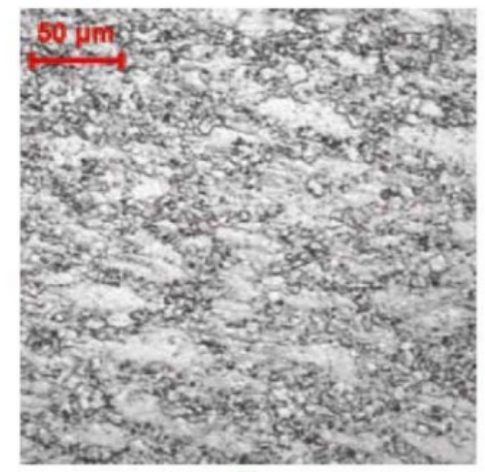

Figure 3. Optical microstructure in different zones of the workpiece: (a) dead zone A; (b) easy deformation zone B; (c) free deformation zone C [5].

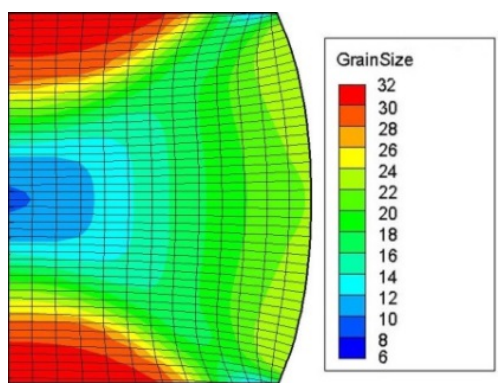

Figure 4. Grain size simulation result of superalloy 718 alloy during non-isothermal forging. 
free deformation zone $\mathrm{C}$, there is a duplex grain microstructure for the incomplete dynamic recrystallization (Figure $3(\mathbf{c})$ ).

The difference between the deformed shapes and the grain size in upsetting simulation and reference [5] could be due to the use of different constitutive equations, friction factors and strain rate in these situations.

\section{Objective Function Definition}

Microstructure changes, specially grain size variations, are very important to the material behavior. Theoretically, the best situation is to obtain a fine, uniform grain size, and large recrystallized volume fraction in the microstructure. In this study, the mean grain size in each finite element was introduced in which not only the recrystallized grain size and recrystallization extent were considered, but also the grain size in no recrystallization part were evaluated as well. The objective was to minimize the variance of mean grain size in all elements and the average of mean grain size in the final product, which is expressed as [9]:

$$
M=\frac{\sum_{i=1}^{N} \int\left(D_{m}{ }^{i}-D_{\text {ave }}\right)^{2} d V_{i}}{\sum_{i=1}^{N E} \int d V_{i}}+\beta\left(D_{\text {ave }}-D_{\text {des }}\right)^{2}
$$

where $N$ is the total number of elements, $D_{m}{ }^{i}$ is the calculated grain size for every element, $\beta$ is the weight factor, $D_{\text {des }}$ is the desired mean grain size and $D_{\text {ave }}$ is the average of mean grain size in the final product, which is expressed as:

$$
D_{\text {ave }}=\frac{\sum_{i=1}^{N} \int D_{m}{ }^{i} d V_{i}}{\sum_{i=1}^{N} \int d V_{i}}
$$

\section{Design Variables Selection and Orthogonal Array Construction}

The volume of ingot was taken as a constant. Ingot height to diameter ratio $H / D$, forging temperature $T$ and compression speed $v$ where chosen as design variables. Uniform and small microstructure of the final forging part was considered the objective function. Ingot height to diameter ratio was $2-3$, the initial forging temperature was in the range of $400^{\circ} \mathrm{C}-600^{\circ} \mathrm{C}$, and the top die velocity was $3-9 \mathrm{~m} / \mathrm{s}$. As shown in Table 3 , each parameter had three levels.

\section{Simulations}

Simulations were run in the order of orthogonal array shown in Table 4, which was made according to Tagushi suggestion, using Abaqus/Explicit finite element code. The workpiece material was IN718 alloy. The young's modulus was 202.7 $\mathrm{Gpa}$, the poisson's ratio was 0.37 and a friction factor of 0.3 between the die and the workpiece was selected. Also, an adiabatic dynamic explicit analysis was chosen because of the high speed of the process. The heat transfers between the 
Table 3. Factors and different levels considered for the simulations.

\begin{tabular}{cccc}
\hline Level & $H / D$ ratio & $T\left({ }^{\circ} \mathrm{C}\right)$ & $v \quad(\mathrm{~m} / \mathrm{s})$ \\
\hline 1 & 2 & 400 & 3 \\
2 & 2.5 & 500 & 6 \\
3 & 3 & 600 & 9 \\
\hline
\end{tabular}

Table 4. Simulation results obtained from Abaqus.

\begin{tabular}{cccccc}
\hline Experiment no & $H / D$ & $T$ & $V$ & $M\left(\mu \mathrm{m}^{2}\right)$ & $S / N$ ratio $(\mathrm{db})$ \\
\hline 1 & 1 & 1 & 1 & 104.23 & -40.3599 \\
2 & 1 & 2 & 2 & 96.11 & -39.6554 \\
3 & 1 & 3 & 3 & 82.25 & -38.3027 \\
4 & 2 & 1 & 2 & 134.36 & -42.5654 \\
5 & 2 & 2 & 3 & 117.82 & -41.42 \\
6 & 2 & 3 & 1 & 94.13 & -39.4746 \\
7 & 3 & 1 & 3 & 151.79 & -43.6249 \\
8 & 3 & 2 & 1 & 128.53 & -42.1801 \\
9 & 3 & 3 & 2 & 117 & -41.3637 \\
\hline
\end{tabular}

die and the workpiece was neglected. Moreover, inelastic heat fraction of 0.9 was selected to consider the effect of heat generation on the temperature rise during deformation.

Microstructure simulation was performed by implementing Table 2 equations into Abaqus. An initial grain size of $32 \mu \mathrm{m}$ was assumed to be uniformly distributed in the workpiece.

\section{9. $(S / N)$ Analysis}

The signal-to-noise $(S / N)$ ratio was adopted to analyze the test results in the Tagushi method. The $S / N$ function is defined as follows:

$$
S / N=-10 \log (M S D)
$$

where $M S D$ is the mean square derivation for the quality characteristics under one trial condition. Usually, there are three categories for quality characteristic. They are: the lower-the-better, the-higher-the-better and the nominal-the better. Regardless of the category of the quality characteristic, a greater $S / N$ ratio corresponds to a better quality characteristic.

The objective function in this work was $M$ which shows grain size and their scattering from an average size. Ideally, both of them needed to be minimized, hence $M$ was a the-lower-the-better quality characteristic. The mean square derivation for the-lower-the-better quality characteristic was given by:

$$
M S D=\frac{1}{n} \sum_{i=1}^{n} y_{i}^{2}
$$

Where $y_{i}$ is the value of the-lower-the-better quality characteristic and $\mathrm{n}$ is the number of the tests for a trial condition.

The result of the microstructure objective function and its $S / N$ ratio in 9 trial conditions were calculated based on Table 3 and is shown in Table 4. The 
average $S / N$ ratio of the microstructure objective function value for each parameter in levels 1 - 3 are shown in Table 5.

Considering average $S / N$ ratios and taking into account the fact that higher $S / N$ ratio is better, the optimum and the poorest combination of forge parameters are shown in Table 6.

Final grain size simulation was run with the optimum and the poorest forge combinations. Results are shown in Figure 5(a) and Figure 5(b). As can be seen in these figures, the red areas in Figure 5(a), which represents unrecrystallized regions, are nearly gone in Figure 5(b). As a result the uniformity is better in Figure 5(b).

\section{ANOVA Analysis}

Variance analysis (ANOVA) was performed, to quantitatively investigate the effect of the process parameters. The overall average $S / N$ ratio is expressed as:

$$
\overline{(S / N)}=\frac{1}{k} \sum_{i=1}^{k}(S / N)_{i}
$$

where $k$ is the number of the tests in the orthogonal array, and $(S / N)_{i}$ is the $S / N$ ratio of the $i^{\text {th }}$ test. The sum of the squares due to the variation from the overall average $S / N$ ratio is:

$$
S S=\sum_{i=1}^{k}\left((S / N)_{i}-\overline{S / N}\right)^{2}
$$

And the sum of the squares due to the variation from the average $S / N$ ratio for the $i^{\text {th }}$ factor is:

$$
S S_{i}=\sum_{j=1}^{l} T_{j} \times\left((S / N)_{i j}-\overline{S / N}\right)^{2}
$$

where $l$ is the number of the factor levels ( $1=3$ in this study), $T_{j}$ is the number of the tests of the $i^{\text {th }}$ factor at the $f^{\text {th }}$ level. The percentage contribution on the th factor is given by

Table 5. Average $S / N$ ratio for each parameter in levels 1 - 3 .

\begin{tabular}{cccc}
\hline Level & $H / D$ & $T$ & $v$ \\
\hline 1 & -39.43 & -42.18 & -40.67 \\
2 & -41.15 & -41.08 & -41.19 \\
3 & -42.38 & -39.71 & -41.11 \\
\hline
\end{tabular}

Table 6. The optimum and the poorest forge parameters combinations.

\begin{tabular}{ccc}
\hline & Optimum level poorest level & \\
\hline$H / D$ & 1 & 3 \\
$T$ & 3 & 1 \\
$v$ & 1 & 2 \\
\hline
\end{tabular}




$$
P_{i}(\%)=\frac{S S_{i}}{S S} \times 100
$$

ANOVA results are shown in Table 7. The results show a strong effect of the height to diameter ratio, and forging temperature, as well as a small effect of the die speed.

\section{Conclusions}

In this study, mathematical models were used to predict the microstructure evolution during forging of a superalloy used in turbine disc after the results were validated by compression testing. A robust process based on Tagushi method was used to determine the optimum combination of forging parameters (height

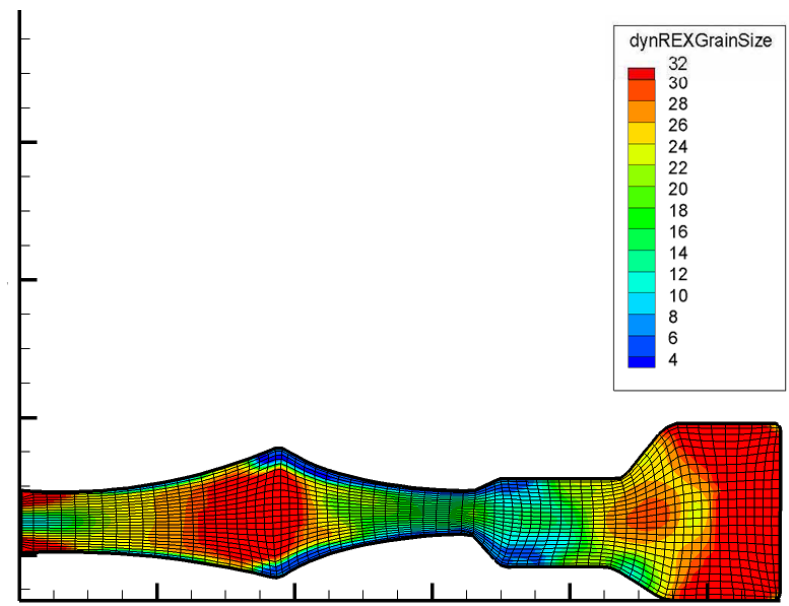

(a)

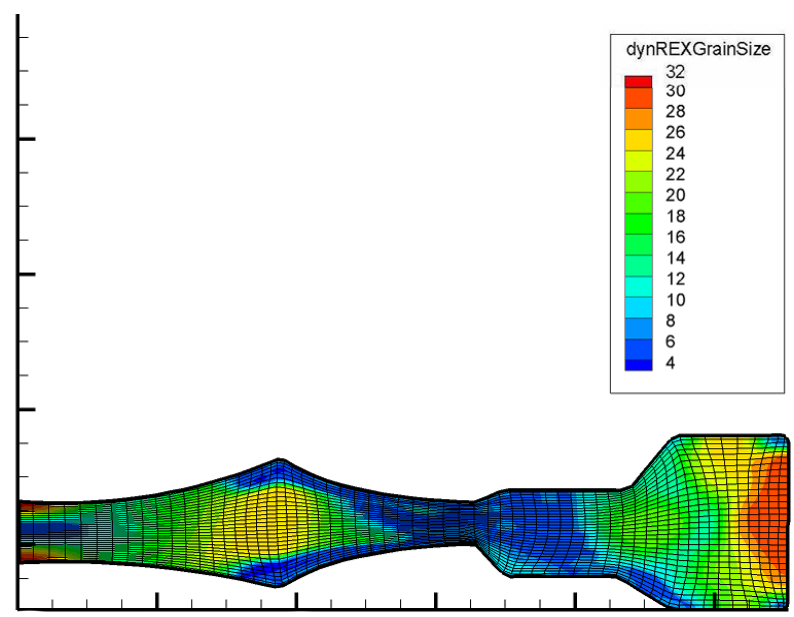

(b)

Figure 4. Grain size simulation for 718 alloy used in turbine disc (a) with the poorest forge parameters combination (b) with the optimum forge parameters combination.

Table 7. Variance Analysis for $S / N$ ratio.

\begin{tabular}{lccc}
\hline & $H / D$ & $T$ & $v$ \\
\hline Contribution ratio & $57.50 \%$ & $40.30 \%$ & $2.20 \%$ \\
\hline
\end{tabular}


to diameter of the ingot, forging temperature and velocity of the top die) and the poorest combination of forging parameters. This was done to obtain a fine and uniform grain size. Two simulations were run based on the above combinations. Simulations results showed more uniform microstructure with more recrystallized volume fraction in forging with an optimum combination of parameters compared with the forging with the poorest combination of parameters. Also, ANOVA analysis was used to quantitatively investigate the effect of each forging parameter on the microstructure. These later results showed a strong effect of height to diameter of the ingot, and the forging temperature compared with the top die velocity.

\section{References}

[1] Azarbarmas, M., Aghaie-Khafri, M., Cabrera, J.M. and Calvo, J. (2016) Microstructural Evolution and Constitutive Equations of Inconel 718 Alloy under Quasi-Static and Quasi-Dynamic Conditions. Materials \& Design, 94, 28-38.

https://doi.org/10.1016/j.matdes.2015.12.157

[2] Azarbarmas, M., Aghaie-Khafri, M., Cabrera, J.M. and Calvo, J. (2016) Dynamic Recrystallization Mechanisms and Twining Evolution during Hotdeformation of Inconel 718. Materials Science and Engineering A, 678, 137-152. https://doi.org/10.1016/j.msea.2016.09.100

[3] Na, Y.-S., et al. (2003) Simulation of Microstructures for Alloy 718 Blade Forging Using 3D FEM Simulator. Journal of Materials Processing Technology, 141, 337-342. https://doi.org/10.1016/S0924-0136(03)00285-1

[4] Medeiros, S., et al. (2000) Microstructural Modeling of Metadynamic Recrystallization in Hot Working of IN 718 Superalloy. Materials Science and Engineering. $A$, 293, 198-207. https://doi.org/10.1016/S0921-5093(00)01053-4

[5] Zhang, H., et al. (2010) Hot Die Forging Process Optimization of Superalloy IN718 Turbine Disc Using Processing Map and Finite Element Method. Proceedings of the Institution of Mechanical Engineers, Part B: Journal of Engineering Manufacture, 224, 103-110. https://doi.org/10.1243/09544054JEM1571

[6] He, X., Yu, Z. andLai, X. (2009) Robust Parameters Control Methodology of Microstructure for Heavy Forgings Based on Taguchi Method. Materials \& Design, 30, 2084-2089. https://doi.org/10.1016/j.matdes.2008.08.039

[7] Park, N., et al. (1997) Two Step Forging of Alloy 718. Superalloy, 718, 625-706. https://doi.org/10.7449/1997/Superalloys_1997_173_182

[8] Shen, G., Semiatin, S. and Shivpuri, R. (1995) Modeling Microstructural Development during the Forging of Waspaloy. Metallurgical and Materials Transactions A, 26, 1795-1803. https://doi.org/10.1007/BF02670767

[9] Gao, Z. and Grandhi, R.V. (2000) Microstructure Optimization in Design of Forging Processes. International Journal of Machine Tools and Manufacture, 40, 691-711. https://doi.org/10.1016/S0890-6955(99)00083-8 
Submit or recommend next manuscript to SCIRP and we will provide best service for you:

Accepting pre-submission inquiries through Email, Facebook, LinkedIn, Twitter, etc. A wide selection of journals (inclusive of 9 subjects, more than 200 journals)

Providing 24-hour high-quality service

User-friendly online submission system

Fair and swift peer-review system

Efficient typesetting and proofreading procedure

Display of the result of downloads and visits, as well as the number of cited articles Maximum dissemination of your research work

Submit your manuscript at: http://papersubmission.scirp.org/

Or contact jamp@scirp.org 